\title{
Cisto dentígero - revisão e apresentação de um caso de localização incomum
}

\author{
Daniele Rizzo Campos Dias* \\ Onofre Quadros**
}

\begin{abstract}
RESUMO
Revisão Bibliográfica sobre a etiopatogenia, distribuiçāo, incidência e evolução do cisto dentígero, incluindo a apresentação de um caso de ocorrência ectópica do $3^{\circ}$ molar inferior em área de apófise coronóide esquerda, em paciente feminina de 44 anos.
\end{abstract}

\begin{abstract}
SUMMARY
Bibliographic review about dentigerous cyst etiopathogenesis, distribution, incidence and evolution, including a case report of a 44-years old - woman with a lower left third molar tooth in coronoide apophisis area.
\end{abstract}

\section{INTRODUÇÃO}

O cisto é definido como uma cavidade patológica revestida por epitélio contendo, usualmente, material líquido ou semi-sólido. Esta cavidade nem sempre se apresenta revestida por epitélio, do ponto de vista anátomo-patológico. Os cistos odontogênicos são derivados do epitélio de desenvolvimento do órgão dentário; dependem, pois, da fase da odontogênese em que se originam. 0 epitélio associado a cada um dos cistos odontogêncos é derivado de uma das seguintes fontes:

- germe dentário

- epitelio reduzido do esmalte de uma coroa dentária

- restos epiteliais de Malassez, remanescentes da bainha de Hertwig

- remanescentes da lâmina dentária

- camada basal do epitélio bucal

O diagnóstico de qualquer dos cistos odontogênicos e sua identificação exata, quanto ao tipo, dependem do exame microscópico do tecido, juntamente com o estudo cuidadoso dos achados clínicos e radiográficos (4).

A Organizaçāo Mundial da Saúde (OMS) classifica os cistos epiteliais em: de desenvolvimento (odontogênicos e nāo odontogênicos) e inflamatórios. O cisto dentígero ou folicular $\boldsymbol{\theta}$ um cisto epitelial de desenvolvimento odontogênico $(5,10)$.

\section{CONSIDERAÇÕES EMBRIOLÓGICAS}

As etapas da Odontogênese compreendem a formaçāo do broto maciço, casquete, campânula e órgåo do esmalte. A fase do broto maciço corresponde a invaginação da lâmina epitelial para o interior do mesênquima, transformando o bordo liso para um ondulado (aparecimento dos brotos epiteliais sendo vinte no total, e cada broto o órgão do esmalte de um temporário). No $5^{\circ}$ mês de vida intra-uterina, ocorre a involução da lâmina dentária gradativamente. Neste processo, pode ocorrer acúmulo de restos epiteliais de Malassez no tecido conjuntivo (importantes na gênese dos cistos odontogênicos), os quais permanecem latentes, podendo, por fatores desconhecidos, serem reativados em sua potencialidade (continuando o processo de formação das estruturas), acarretando neoformaçōes irregulares no tempo e no espaço. Seguemse, então, as fases denominadas casquete e campånula com a formação da Papila Dentária que dá origem à Polpa e à Dentina, através da ação das células epiteliais sobre o mesênquima, organizando a forma do futuro dente (ação modeladora). A modificaçăo do aspecto do tecido mesenquimático forma a papila dentária, esta uma diferenciação eminentemente celular, que ocorre no interior da concavidade da estrutura epitelial. Ocorre também uma diferenciaçăo fibrocelular ao redor do conjunto que dará origem aos elementos de sustentaçāo do dente, saco dentário. 0 epitélio do órgão do esmalte induz as células mesenquimáticas mais superficiais da Papila Dentária a diferenciar-se em odontoblastos, estes iniciam a formar dentina. As células epiteliais da camada interna do órgāo do esmalte, ameloblastos, começam a elaborar esmalte.
Quando completa-se a Odontogênese, - folículo dentário está composto por: órgảo do esmalte, papila dentária e saco dentário (1).

$\mathrm{O}$ cisto dentígero origina-se depois que a coroa encontra-se completamente formada, devido à alteração do epitélio adamantino, com acúmulo de líquido entre o epitélio reduzido do esmalte e a coroa do dente $(1,4,9)$.

\section{DEFINIÇÃO}

O cisto dentígero ou folicular, é uma lesăo cística que apresenta no seu interior a coroa de um dente nāo erupcionado, incluso ou impactado.

\section{NATUREZA DA LESÃO}

É uma patologia de natureza benigna, com grande potencial de transformação ameloblástica, podendo tornar-se o mais agressivo dos cistos odontogênitos.

Grande é a chance de evoluir para ameloblastoma.

\section{LOCALIZAÇÃO}

Segundo a literatura, a localizaçăo preferencial em ordem decrescente de frequência é a seguinte: terceiro molar inferior, terceiro molar superior, canino superior e segundos pré-molares inferiores. Este cisto pode estar associado a dentes supranumerários. Não há relato de associação com dentes temporários $(1,2,5$, 9).

\section{* Internato em Estomatologia \\ HCPA/UFRGS - 1990}

** Prof. Titular de Patologia - FO/UFRGS 


\section{EPIDEMIOLOGIA}

O cisto dentígero é o responsável por volta de um terço de todos os cistos odontogênicos (8).

Segundo Shear (5) a incidência mundial por milhăo por ano é de:

- negros - 1,18

- negras - 1,22

- brancos - 9,92

- brancas - 7,26

Conforme este mesmo autor, há uma frequência muito maior em brancos do que em negros (para outros autores a predileçăo racial seria pouco evidente) (5).

A maioria dos autores relata que a idade de maior ocorrência é entre 20 e 30 anos. Segundo Tommasi, há relatos de casos em crianças; $\theta$, o potencial de transformaçăo ameloblástica que atinge o máximo em torno dos 30 anos reduz-se nitidamente após os 35 anos (9).

\section{CARACTERÍSTICAS CLÍNICAS}

Está sempre associado à coroa de um dente incluso ou impactado e também pode estar envolvendo um odontoma complexo ou um dente supranumerário (4).

Apresenta crescimento lento $\theta$ é assintomático, exceto se infectados secundariamente. Pode atingir um tamanho considerável, devido a expansāo óssea com subsequente assimetria facial, deslocamento de dentes vizinhos e daquele que the deu origem, reabsorçāo das raízes dos dentes adjacentes $\theta$ a dor. Em decorrência da destruiçăo óssea pode ser facilmente palpado percebendo-se flutuaçăo na regiảo $(1,4,5,6,9)$.

Quando associado a um canino superior ocorre uma expansăo da regiăo anterior da maxila e que, superficialmente, pode sugerir uma sinusite aguda ou celulite (4).

\section{CARACTERÍSTICAS RADIOGRÁFICAS}

O exame radiográfico é valioso no diagnóstico da lesão cística. 0 aspecto radiográfico é característico dos cistos mostrando uma zona de destruiçăo óssea do tipo cavitário, caracterizado por uma imagem radiolúcida devido à ausência de estruturas ósseas intrínsecas ou de revestimento, usualmente arredondada ou oval, com contornos lisos $\theta$ bem definidos, com uma linha radiopaca margeando o osso adjacente. Esta imagem radiográfica deve ser igual ou superior a $2,5 \mathrm{~mm}$ de extensăo, para diferenciá-la da imagem do saco dentário e sempre envolvendo a co- roa de um dente retido, a partir da porção cervical $(1,2)$.

Podem ser classificados de acordo com o local onde se desenvolvem em relação a coroa do dente, em laterais, centrais ou circunferenciais.

Surprendemos os cistos dentígeros nos levantamentos radiográficos de rotina, quando já existe sintomatologia clínica ou quando o dente nāo erupciona e buscase a causa.

O cisto dentígero é dito central quando a imagem radiolúcida envolver simetricamente a coroa do dente retido, lateral quando a imagem radiolúcida envolver parcialmente a coroa do dente retido e circunferencial quando ocorre de todo o dente encontrar-se envolvido pela área radiolúcida circunscrita $(1,2,4,5,9)$.

Geralmente é uma lesāo unilocular, mas podendo se apresentar de forma multilocular $(1,2,4,9)$.

\section{TRATAMENTO}

O tratamento do cisto dentígero é eminentemente cirúrgico, e a técnica dependerá do tamanho e localizaçāo da lesāo, bem como da idade e condiçōes gerais do paciente. Para as lesōes de pequeno porte prefere-se a enucleaçăo com a curetagem ou ressecçảo em bloco da lesāo cística. Cabe salientar, novamente, que devido a sua potencialidade agressiva, há risco de recorrência de lesão cística, pela simples permanência de restos epiteliais, năo sendo esta novamente um cisto dentígero $(4,5,9)$. Segundo Taylor (8), certos autores acreditam que em todos os cistos grandes ou multiloculares deve sempre ser feita uma biópsia de congelaçảo antes da enucleaçăo completa da lesão. Conforme, ainda, Taylor (8), a proliferaçāo da parede ameloblastomatosa deve ser manipulada diferentemente do ameloblastoma clássico (a intervenção cirúrgica mais ampla deveria ser injustificável, do ponto de vista da reabilitaçāo do paciente e do prognóstico favorável do ameloblastoma intracístico). Se as recorrências aparecem, elas são semelhantes às lesōes incipientes pequenas, e devem ser tratadas como o ameloblastoma clássico (com uma excisāo em bloco, incluindo margens adequadas de osso normal). 0 paciente deve ser proservado, até a conclusäo definitiva da cura, por meios clínicos e radiográficos. Por isso, $e$ obrigatório o exame histopatológico da peça cirúrgica removida, prevenindo uma eventual transformaçāo ameloblástica (9).

\section{EVOLUÇÃO}

Além da possibilidade de uma simples recorrência de uma lesāo cística com a remoçāo cirúrgica incompleta da lesāo cística, existem três complicaçōes que devem ser salientadas $(4,9)$ :

1. Desenvolvimento de um ameloblastoma, a partir do revestimento epitelial ou dos restos de epitélio odontogênico da parede do cisto.

2. Desenvolvimento de um carcinoma epidermóide a partir das mesmas fontes epiteliais.

Para Taylor (8), o tratamento do cisto dentígero é controverso. A ocorrência rara do carcinoma de células escamosas nos cistos odontogênicos não deve ser interpretado como necessidade inicial de cirurgia radical, mas deve ser um estímulo ao exame histopatológico de todos os cistos odontogênicos. O objetivo primário do tratamento de qualquer lesão dirige-se para a remoçăo completa do tecido tumoral.

Jackson (3) relata caso de paciente com um quadro terminal pulmonar cuja biópsia realizada mostrou carcinoma de células escamosas. Concomitante, havia um cisto odontogênico infectado (flora anaeróbica - cultura de aspiraçāo), com degeneraçāo ameloblastomatosa, localizado na mandíbula.

3. Desenvolvimento de um carcinoma mucoepidermoide, um tipo de tumor de glândula salivar, a partir do epitélio limitante do cisto que contém células mucosas.

A relaçāo entre o cisto dentígero e o ameloblastoma é de aproximadamente $17 \%$, sendo que a tendência para transformaçāo do epitélio neoplásico sob a forma de ameloblastoma é mais pronunciada no cisto dentígero do que em qualquer outro cisto odontogênico. Devido a impossibilidade de determinar quando o cisto dentígero está evoluindo para ameloblastoma por meios clínicos ou radiográficos, o exame histológico da peça cirúrgica torna-se de vital importância (9).

Segundo Taylor (8), 15 a $33 \%$ de todos os ameloblastomas surgem de cistos foliculares pré-existentes. Histologicamente, o cisto dentígero lembra cistos radiculares. O epitélio cístico é do tipo pavimentoso estratificado, com espessura variável de poucas ou muitas camadas de células. 0 revestimento conjuntivo da bolsa cística é constituído de fibras colágenas, espesso, com infiltrado linfoplasmocitário $(1,9)$

\section{PROGNÓSTICO}

O prognóstico é favorável, com o diagnóstico clínico e radiográfico, preferencialmente precoce, seguido da remoçāo cirúrgica correta e preservaçāo do paciente até a cura definitiva. 


\section{CASO CLÍNICO - CISTO DENTÍGERO}

A paciente M.O.S.S., sexo feminino, 44 anos, casada, cor parda, natural de Vacaria (RS) e profissäo do lar, em dezembro de 1989 procurou o Serviço de Estomatologia do HCPA. Clinicamente, apresentava uma lesăo expansiva em mandíbula esquerda, que provocava uma assimetria facial importante. Notava-se, ainda, que havia uma limitação parcial na abertura bucal. Pela anamnese, soube-se que a evoluçāo do quadro remontava há 9 anos atrás, quando já notava alteraçăo na regiāo esquerda. O crescimento foi progressivo. E no último ano, manteve-se estável. Não havia referência à dor.

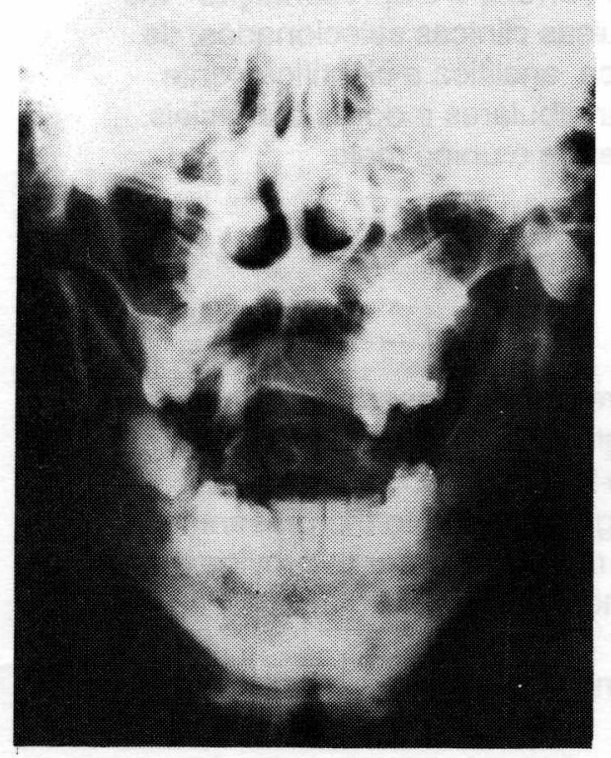

O exame extra-bucal demonstrava aumento de volume facial à esquerda, firme à palpaçāo. Intra-bucalmente apresentava um aumento de volume à esquerda na regiāo de tuberosidade.

Foram solicitadas, entăo, as seguintes radiografias: panorâmica, laterais oblíquas, póstero-anterior e periapical.

Pode-se observar, radiograficamente, na mandíbula esquerda, uma área radiolúcida, na regiảo de apófise coronóide, que apresentava expansāo de cerca de $3,5 \mathrm{~mm}$ de diâmetro que continha no seu interior o terceiro molar inferior esquerdo, em posição invertida. A lesão é de forma oval, com contorno liso, definido e esclerótico. Na mandíbula direita, se observa o terceiro molar inferior em posiçāo horizontal associado a uma imagem radiopaca com densidade de esmalte, irregular, medindo cerca de $1,5 \mathrm{~mm}$ de diâmetro, sugerindo coroas de dentículos e envolvida por um halo radiolúcido de limites precisos.

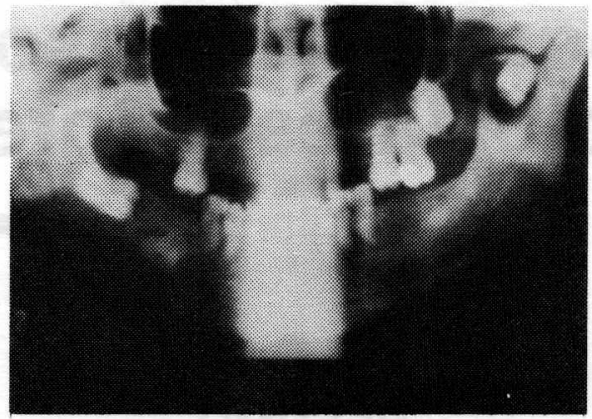

Em março de 1990, foi realizada aspiração intra e extra-bucal da lesăo na mandíbula esquerda. Na aspiraçāo extra-bucal houve drenagem de pus e sangue, o que poderia sugerir que o cisto estivesse infectado. A agulha penetrou em uma cavidade vazia $\theta$ extensa.

Em abril de 1990, procedeu-se a remoçāo cirúrgica da lesāo cística e do molar associado a esta, localizada na regiāo de apófise coronóide esquerda. Removido, também, o terceiro molar inferior direito incluso e a massa radiopaca localizada na mandíbula direita.

O exame histopatológico, confirmou o diagnóstico presuntivo de Cisto Dentígero na regiāo da apófise coronóide esquerda. A massa radiopaca no lado direito mostrou, apenas, tecido ósseo reacional.

A paciente evoluiu bem e continua em acompanhamento ambulatorial regular. Apresenta melhora na abertura bucal com fisioterapia.

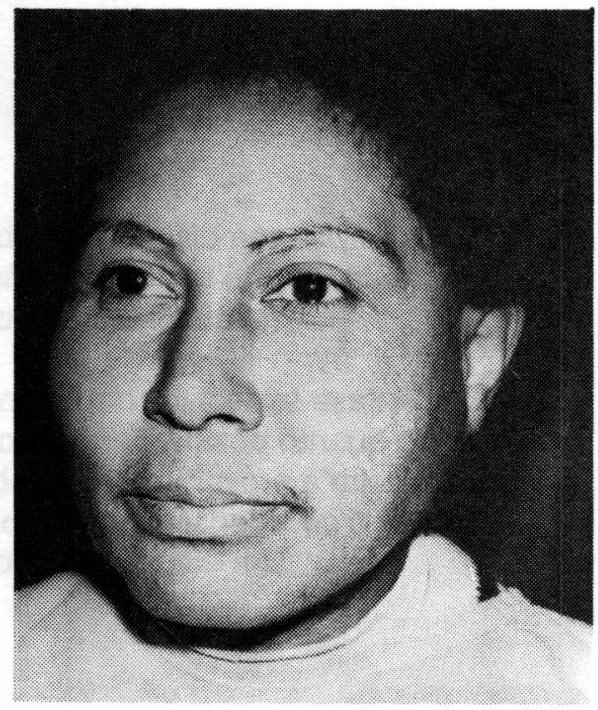

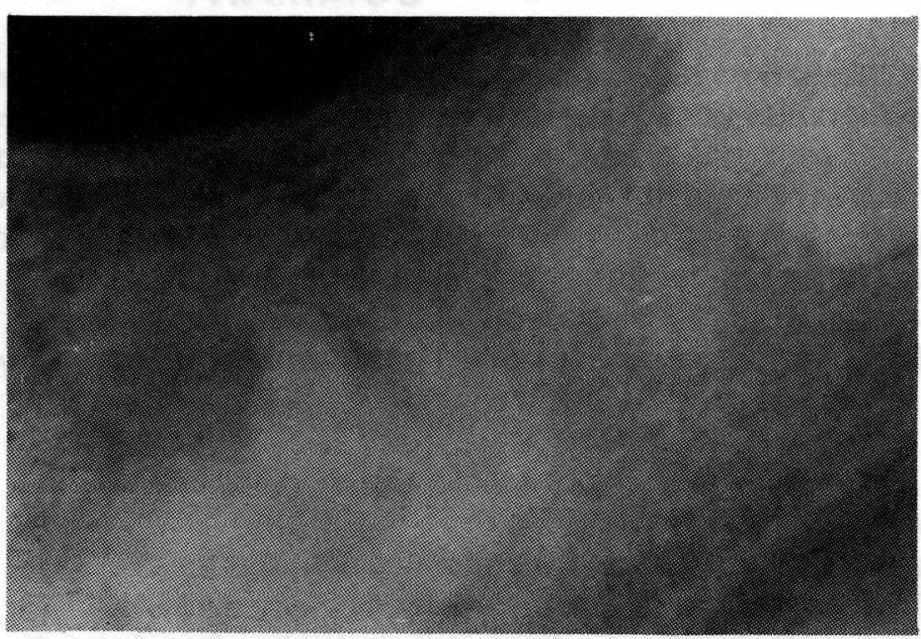

\section{REFERÊNCIAS BIBLIOGRÁFICAS}

01. EBLING, H. - Cistos e Tumores Odontogênicos. Porto Alegre, UFRGS, $3^{2}$ ed., 1977.

02. FREITAS, A. de; ROSA, J.E.; SOUZA, I.F. e Radiologia Odontológica, $2^{a}$ ed., Artes Médicas, 1988.

03. JACKSON, R.F.; KRAMER, H.S.; HYDE, G.H.; EISENBERG, E. \& TOPAZIAN, R.G. - Dentigerous cyst of the mandible with ameloblastomatous changes. J. Oral Maxillofac. Surg. 41(6):407-8, June, 1983.

04. SHAFER, W.G.; HINE, M.K. \& LEVY, B.M. Tratado de patologia bucal, $4^{a}$ ed., Rio de Janeiro: Guanabara, 1987.

05. SHEAR, M. - Cistos da Regiāo Bucomaxilo- facial: Diagnóstico e tratamento, $2^{2}$ ed., Livraria Santos Editora, 1989.

06. SPOUGE, J.D. - Patologia Bucal, $2^{a}$ ed., Editora Mundi S.A.I.C. y F., 1977.

07. STANLEY, H.R. \& PANNKOK, E. - Age changes in the epithelial components of follicles (dental sacs) associated with impacted third molars. Oral Surg. 19(1):128-39, Jan., 1965

08. TAYLOR, R.N.; MENELL, H.B. \& WILLIAN, A.C. - Dentigerous cyst with ameloblastomatous proliferation: report of case. J. Oral Surg. 29(2):136-40, Feb. 1971.

09. TOMMASI, A.F. - Diagnóstico em Patologia Bucal, $1^{\text {a }}$ ed., Artes Médicas, 1988.

10. TORLONI, H.; PINDBORG, J.J.; KRAMER, I.R.H. - Tipos Histológicos d Tumores Odontogênicos, cistos dos Maxilares e lesōes afins. Organização Mundial da Saúde, 1972. 